\title{
TRICOMONIASIS VAGINAL
}

\author{
Rodrigo A. Gutiérrez Sa:nz
}

Alumno del curso de Clínica Ginecológica

Es la tricomoniasis vaginal entidad de mucha importancia en la práctica médica diaria, no solamente por la enorme incidencia de este parasitismo, como por la variada sintomatología que ella presenta ,muchas veces espectacular por su dramatismo. Y, se le debe prestar particular atención al poder patógeno del flagelado Trichomonas Vaginalis como agente etiológico responsable de colpitis e infecciones urinarias bajas, porque las estadísticas de los distintos autores dan una frecuencia de infestación, variable entre el 10 y el 60 por 100 entre todas las enfermas que presentan el sintoma leucorrea, y el 80 por 100 en las que sufren una colpitis. En la gran mayoría de los casos la infestación produce molestias subjetivas en las pacientes; otras veces, el parasitismo puede pasar inadvertido. Muy diciente es el recuerdo estadístico de Mohr, de la Clínica del Profesor Schroeder, en Kiel (1) quien ha encontrado por examen microscópico, tricomonas en la secreción vaginal de un 41 por 100 de casos y en el 21 por 100 , mediante cultivos, o sea un 62 por 100 de las mujeres examinadas. En el 52 por 100 de las mujeres examinadas y que se encontraron genitalmente sanas, se comprobó la existencia de dicho flagelado, y no se encontró en el 29 por 100 de casos con flujo.

Las complicaciones en tramos bajos del aparato urinario aparecen con frecuencia, convirtiendo a la enferma y la portadora en fuentes potenciales de difusión y contagio (2).

Las anteriores consideraciones, unidas a la indicada frecuencia de la tricomoniasis, nos obligan a desechar la opinión de la banalidad de esta infestación y a poner en juego todos los medios posibles para llegar a un diagnóstico seguro y establecer una terapéutica eficaz y oportuna. 


\section{Patogenia y Epidemiología}

Aún no hay completo acuerdo sobre muchos puntos de estas cuestiones. Mientras en algunas publicaciones se sostiene la tesis de la posible colonización y ataque del flagelo en una mucosa de caracteres normales, otros autores piensan que para el Trichomonas Vaginalis resulte patógeno, es preciso que exista una deficiencia estrogénica con alcalinización del medio y la presencia de una flora impura en la vagina (3).

Por fin, algunos piensan que tales condiciones pueden interpretarse como efecto y no como causa de la parasitación tricomoniásica, puesto que está demostrado que el flagelado interfiere más o menos el desarrollo de los bacilos de Dŏderlein y al reducir en consecuencia la acidificación del medio, prepara el terreno a los gérmenes que integran esa flora impura.

En cuanto a la Epidemiología, se admite la trasmisión directa y rara vez la indirecta, por objetos contaminados. Este problema está intimamente relacionado con la frecuencia de la uretritis tricomoniásica en el varón. Efectivamente, según Drummond y Karnaky (4) del 25 al 80 por 100 de los maridos de pacientes con colpitis por tricomonas son portadores del flagelo y esta relación es tan importante y tan constante, que justifica la opinión de Allison, de que la tricomoniasis debiera considerarse como la "séptima enfermedad venérea". En la actualidad se sostiene que del 20 al 25 por 100 de los casos de uretritis no gonocócica están causados por el Trichomonas Vaginalis, e incluso que el 10 por 100 de los varones aún sin molestias, son portadores del parásito especialmente en aquellos núcleos sociales en que se descuidan más las prácticas higiénicas.

Lowsley (5) trae al respecto un estudio sobre la uretritis tricomoniásica en el varón y le señala un 35 por 100 dentro de la uretritis. Al respecto dice; aunque la mayoría de los pacientes buscan consejo médico debido a una secreción molesta con sintomas inflamatorios marcados, es también probable que muchos hombres se infecten durante el coito y, aunque alberguen el organismo, sufran una reacción tan ligera que no se enteren de la infección hasta que otro organismo invada la uretra y se establezca una infección mixta. A menudo, el único síntoma es un flujo ligeramente acuoso. Es probable que los pacientes que han tenido gonococcia atribuyan los síntomas a una recidiva de esta enfermedad. La secreción al comienzo es mucosa, pero después 
se hace rápidamente purulenta. Y así como la uretritis tricomoniásica en el varón se presenta con iguales síntomas que la procucida por otros organismos patógenos, también puede manifestarse con infiltración periuretral y hasta con estrechez del conducto. Otra localización en el hombre son la próstata (3 por 100 según el estudio de Stuhler (6) de la Clínica Mayo, después del examen de 32.000 pacientes), vesículas seminales 1 caso entre 300 y las localizaciones en la vejiga, más frecuente que las anteriores.

Aunque el tema de la tricomoniasis del varón ha sido poco subrayado por los urólogos, no cabe duda de la realidad de estos hechos, que imponen en la práctica la cuidadosa investigación de un posible parasitismo en los maridos de las enfermas. Y elio es especialmente importante toda vez que se quiera hacer el tratamiento definitivo de la tricomoniasis en la mujer, esto es, no pasar por alto el posible papel infectante del marido. Es por ello que la práctica aconsejada del examen en fresco, un análisis por coloración de Sorel, que ya de rutina se hace en Bogotá, aplicado a secreciones uretro-prostáticas, entre otras cosas por insinuación del profesor doctor Fidel Torres León (7). Al respecto existe un trabajo de grado del doctor Emiliano Rengifo en el cual se pone en evidencia la importancia de esta técnica. En caso de positividad, el tratamiento deberá ser simultáneo en ambos cónyuges sin olvidar que, en la patología de las recidivas juega un papei importante el acantonamiento del parásito en órganos de topografía paragenital: uretra, vegija, glándulas de Skene y Bartholino, a partir de las cuales, y aprovechando el medio favorable para reproducirse que le brinda la sangre menstrual, reinfecta la vagina cuando ésta, espontanea o terapéuticamente, se había librado del parásito.

\section{El parásito}

Este protozoo flagelado fue descubierto por Doneé en 1836 (8) y se le describe mastigóforo de forma piriforme, que mide de 10 a 15 micras de largo por 7 a 10 de ancho; posee tres flageos anteriores libres y uno posterior, más grueso, unido al cuerpo por una membrana ondulante; tiene un solo núcleo; un axostilo y citostoma; su protoplasma es granular y con varios inclusiones (9). Nunca forma quistes como fase de resistencia, aunque algunos le describen "formas inmóviles sin flagelos aparentes que podrian interpretarse como quistes" (10) (11). El parásito 
es orgánicamente lábii y los agentes físicos acaban fácilmente con él fuera de su estado parasitario normal. El calentamiento por encida de los 40 grados, la exposición al sol y la refrigeración, el agua, la concurrencia bacteriana, la desecación, ie hace morir en pocos minutos. En el cultivo especial crece con determinadas exigencias pero pierde fácilmente su aparato locomotor. Y es esta escasa resistencia la que dificulta las posibilidades de transmisión indirecta. Se admiten tres variedades de tricomonas infectantes del organismo humano: ia $\mathrm{Tr}$. Vaginalis, la $\mathrm{Tr}$. Bucalis y la Tr. Hominis. Mucho se ha escrito y experimentado sobre si las tres formas citadas son de un mismo organismo o si son organismos diferentes. M. L. Pérez (12) ha experimentado infectar vaginas con las tres variedades antes citadas, ya que morfológicamente los parásitos son idénticos mas únicamente ha conseguido probar poder patógeno en la tricomonas vaginalis. En el mismo sentido Bauer (13) empleando variedades Bucalis y Hominis, solamente en casos contados consiguió su adaptación al medio vaginal, siendo la $\mathrm{Tr}$. Bucalis más adaptable que la $\mathrm{Tr}$. Hominis. Pero nunca consiguió demostrar una colpitis o alteraciones del flujo en las mujeres voluntariamente inoculadas.

La investigación de Tricomonas en enfermas sospechosas, debe convertirse en una exploración sistemática en aquellas pacientes cuya leucorrea y molestias no tengan una muy clara explicación. Hay varios métodos adecuados para la demostración del parásito y en muchas ocasiones habrá que servirse de más de uno para lograr aclarar dudas sobre la existencia o no de tricomonas.

a) Examen en fresco. La simple observación directa, en fresco, permite la visualización dei flagelo con sus movimientos característicos. Una técnica recomendable consiste en el arrastre de parte de la secreción que recubre las paredes vaginales, bien con una espátula de ángulos romos, bien sencillamente con el dedo enguantado, evitándose siempre el asa de laboratorio, se coloca una gota del flujo así obtenido sobre el porta y se añadirán de dos o tres gotas de solución fisiológica, y una vez mezclado se tapará con el cubre objetos. Para observar la movilidad de los parásitos es condición indispensable una temperatura ambiente no excesivamente fría, y la cuidadosa omisión de antisépticos.

b) Coloración. A este medio debe recurrirse cuando el frotis deberá ser examinado al microscopio en un momento posterior 
a la obtención. El uso de colorantes ayuda a un mejor contraste del parásito especialmente de los elementos flagelados.

Cuando la investigación se realiza en seguida de la obtención del producto en fresco, se puede utilizar como colorante la solución al $20 \%$ de azul briliante de Cresilo en suero salino. El colorante se homogeniza con el producto extraído de la vagina sospechosa, se protege con un cubre objetos y se lleva al microscopio. Como las tricomonas no toman el azul de cresilo, se destacan fuertemente sobre un fondo coloreado.

Los frotis desecados se tratan de elección según el método de May Grünwald Giemsa, donde las tricomonas aparecen con su protoplasma teñido en un color azulado, núcleo violeta, cromatina finamente granulada y flageios coloreados de rojo. El método de coloración de Gram, es igualmente demostrativo; pero debe realizarse una tinción de fondo con Fuchina al 2 por 1.000 , durante cinco minutos, capaz de colorear los flagelos, fundamental elemento distintivo.

c) Cultivo. Han sido propuestas considerable cantidad de medics: con hormonas, con vitaminas, suero de embarazada, cisteína, ec. El PH de los cultivos debe ajustarse al $6 \frac{1}{2}$ y a temperaturas de 37 grados, y libres de gérmenes asociados para lo cual deben añadirse penicilina y estreptomicina y coiocarse en tubos en " $U$ " para evitar la proliferación de hongos en profundidad.

Aun sin entrar en más prolijos detalles sobre el punto, baste subrayar que solamente laboratorios muy especializados podrían proporcionarnos datos prácticos basados en el cultivo de Trichomonas.

Clínica. El flujo por Tricomonas, el más frecuente entre los infecciosos, es purulerłto, espumoso, de reacción generailmente ácida, y se pueden presentar en las paredes vaginales, en los labios y an el cuello, edema, enrojecimiento, puntos petequiales y hasta ulceraciones. Además pueden ocasionar cistitis, prurito y ardor (14). La consistencia líquida y fluída, el color blanquecino, la presencia de pequeñas burbujas de aire y la propiedad irritativa o cáustica que se pone de relieve a nivel de los genitales externos y aun de la cara interna del muslo, hacen sospechar al clínico la presencia de Tricomonas (15).

Pero en cierto número de casos, la presencia de Tricomonas Vaginales puede no acompañarse de ninguna sensación de malestar acusada por la paciente. Sin embargo, hasta en estos ca- 
sos, hecho un cuidadoso estudio, se descubren signos de infección que la interesada no interpreta como anormales, y en la mayoría el examen revela alteraciones objetivas, más o menos notables, vulvovaginales.

En resumen, la observación más frecuente, y en cierto modo característica, comprende las siguientes manifestaciones:

1) Flujo de origen electivamente vaginal; fluído, de coloración amarillo-verdoso y de aspecto espumoso.

2) Prurito intenso; escozor que radica en las partes pudendas, sobre las que contacta la secreción.

3) Con frecuencia disuria y dispareunia.

4) Colpitis que puede llegar a la forma ulcerativa vulvovaginal.

En algunos casos dominan el cuadro las molestias urinarias: disuria, polaquiuria, tenesmo, etc., manifestaciones de una.uretrocistitis especifica, que se diagnostica al descubrir el parásito en el sedimento urinario.

En otros, aunque con carácter excepcional, la infestación asciende a tramos supravaginales del aparato genital y parecen cervicitis, salpingitis crónicas e incluso abscesos pelviperitoneales; hasta en ei contenido de quistes de ovario se ha llegado a descubrir el tricomonas (16).

Diagnóstico positivo. El diagnóstico positivo se hace por la comprobación del parásito al microscopio. Por considerarlo de utilidad práctica, me permito transcribir la técnica recomendada por el doctor Gómez Vesga, en el Primer Congreso Colombiano de Obstetricia y Ginecología, para la toma de muestras de secreciones vaginales:

1) Se introduce el espéculo hasta el tercio interno de la vagina sin usar más lubricante que agua destilada o Suero Fisiológico ya que las grasas dificultan especialmente el diagnóstico de tricomonas y amibas.

2) El escobillón se humedece en el flujo localizado en el tercio interno vaginal y una vez que éste aparezca en la mayor impregnación posible se sumerge en 1' c. c. de Suero Fisiológico o agua destilada contenidos en un tubo de ensayos, el cual puede remitirse al laboratorio tapado con un algodón o un corcho según las condiciones del transporte. Esta muestra se podrá utilizar para el estudio de Tricomonas, hongos, levaduras y piocitos 
en un examen en fresco entre lámina y laminilla y al mismo tiem. po para el examen general por coloración de la flora bacteriana presente.

3) Un segundo escobillón puede impregnarse lo mismo que el anterior y remitirse al laboratorio dentro de un tubo de ensayo estéril (si el tiempo que ha de transcurrir entre la toma de la muestra y el examen es corto) o en un tubo conteniendo $1 \mathrm{c}$. c. de medio de cultivo estéril (caldo nutritivo o caldo de triptosa fosfato DIFCO) cuando el examen se ha de practicar varias horas después.

Esta muestra es de gran utilidad para los estudios bacteriológicos por cultivos del Gonococo, Estreptococo, Eistafilococo, Neumococo, etc.

4) Toma del Ph: por medio de otro escobillón impregnado en al flujo puede humedecerse un papel indicador universal el cual según el color a que vire nos dará en una forma bastante rápida y suficientemente exacta para el caso. La reacción y el $\mathrm{Ph}$ del flujo son muy importantes de tener en cuenta no sólo por la relación que se dice existe entre éste y el agente infeccioso presente sino también porque es una guía para determinados tratamientos.

Tratamiento. El tratamiento de la tricomoniasis vaginal aún no se ha resuelto y buena prueba de ello es la profusión de remedios y orientaciones terapéuticas que dan los diferentes autores, sin que se recomiende ninguna como absolutamente efectiva.

La idea de la mayoría de los especialistas en la materia es que el tratamiento debe realizarse tanto en la enferma como en su marido, para obtener un porcentaje mayor de éxito. Por otra parte ha de observarse que un solo tratamiento, aun bien conducido, rara vez es decisivo, y que la frecuencia de las recidivas impone un examen severo y repetido antes de dar de alta definitivamente a la paciente.

Con estas observaciones doy a continuación los principales tratamientos, pudiendo escoger uno cualquiera, o bien, conjugándolos indistintamente a juicio del médico.

a) Acidificantes. Mediante el empleo de lactosa beta, combinado con lavados en los que se utiliza una solución ácida, por ejemplo una cucharada de ácido acético en un litro de agua, tratando de elevar así el Ph - disminuído en la infestación tricomoniásica - a sus valores normales, favoreciendo en consecuencia el 
desarrollo de bacilos Dŏderlein, con capacidad de crear una antibiosis natural.

Allen (17), creador del método, preconiza la insuflación diaria de lactosa, durante dos semanas, realizando en el mismo plazo, por las mañanas, lavados con la solución anotada de ácido acético, o con ácido láctico, una cucharada por tres litros de agua. Transcurridos los quince días, la enferma coloca diariamente durante dos meses consecutivos, un óvulo que contiene media a una onza de lactosa beta, sin suspender el tratamiento los días menstruales, época en que es habitual la exaltación de la virulencia del parásito.

Aconseja, además, combinar el empleo de los azúcares acidificantes, como la lactosa beta y dextrosa, con antisépticos, como el Diodoquin, elemento al parecer destructor de tricomonas. La preparación ya combinada de estos dos tipos de productos existe en el comercio con el nombre de Floraquin y se expende en tabletas, para colocar, previamente humedecidas, en el fondo de saco vaginal posterior; se utilizan dos tabletas, una por la mañana y otra por la noche, durante siete días; luego una tableta solamente, por la noche, otra semana y una tableta cada dos días la tercera semana. Durante las reglas es preciso el uso frecuente de lavados ácidos y al terminar las tres semanas de tratamiento se seguirá con una dosis de sostenimiento, consistente en el empleo de una o dos tabletas a la semana, durante tres meses.

Con una finalidad semejante se ha propuesto el empleo de cuitivos lácticos. Brady y Reid (18), divulgadores del método, colocan en la vagina, después de seca, dos tabletas conteniendo Lactobacillus Vulgaricus, y ocluyen el conducto; la aplicación se repite cinco días, constituyendo un ciclo; después de tres ciclos, el tratamiento lo realiza la propia enferma, colocándose dos tabletas a la semana durante 2 a 4 semanas.

b) Picrato de plata. Es una de las técnicas de tratamiento en seco que cuenta con un número crecido de adeptos. Las aplicaciones, que debe realizar el médico, consisten en la insuflación vaginal de Picrato de Plata, muy finamente pulverizado. con caolín; una parte de picrato por 99 de caolín. La pulverización se hace tras la limpieza cuidadosa de la mucosa con agua oxigenada, y secado. Los días sucesivos, durante seis, se colocará un óvulo conteniendo 0.12 grs. de Picrato de Plata, y a continuación se repite todo el ciclo del tratamiento. La enferma 
ciebe ser vigilada durante tres o más meses, realizándose investigación de tricomonas después de cada período menstrual.

c) Luz ultravioleta. Comprobada la escasísima resistencia del tricomonas a las radiaciones solares, y especialmente a las que integran la zona ultravioleta, se ha propuesto la aplicación intravaginal de este tipo de rayos en el tratamiento de la tricomoniasis. El mayor inconveniente del método es que la mucosa de la vagina resiste muy mal la irradiación, presentándose rápidamente reacciones eritematosas y exudativas.

d) Arsenicales. Los arsenicales pentavalentes, del tipo del Carbarsone, y del Stovarsol, constituyen una terapéutica ya clásica en el tratamiento antitricomoniásico, y se sigue utilizando pese a lo irregular de sus resultados, satisfactorios en algunos casos e inoperantes en otros. La administración se hace en forma de tabletas intravaginales, que contienen bien el arsenical solamente o combinado con distintas sulfonamidas.

e) Antibióticos. Algunos de los antibióticos de actual disposición se muestran eficaces en el tratamiento de la tricomoniasis, y dada la inocuidad general del empleo de estas sustancias, es indudable que su introducción en clínica presente un avance considerable.

McVay y colaboradores (19) demostraron que la aureomicina destruye in vivo las tricomonas. Sin embargo, la administración por vía digestiva de la droga no logra la esterilización de las pacientes.

La técnica terapéutica en uso consiste en la aplicación local de dosis de 500 mgrs. de Aureomicina en 2 gramos de talco finamente pulverizado, mediante insuflación que se repite al día siguiente, al cuarto y al sexto días. A partir de este último, y por un tiempo variable, la paciente coloca una cápsula conteniendo $250 \mathrm{mgrs}$. del antibiótico, profundamente, en la vagina. Los resultados son buenos: las recidivas son escasas en relación con el porcentaje de curaciones.

La terramicina, sería capaz de hacer desaparecer las tricomonas en 24 horas, y de curar una colpitis en una semana. Primero debe realizarse una limpieza mecánica de la vagina; la tarde del mismo día la enferma se coloca un óvulo de terramicina, preparación vaginal, tratamiento que se repite durante siete días. Después de los períodos menstruales, se reemprende el tratamiento. 
Tratamiento durante el embarazo. Durante el embarazo las condiciones existentes en el tracto genital favorecen el desarroilo del flagelado, de forma que la infección se observa con mucha frecuencia en las mujeres grávidas.

El estado no contraindica el tratamiento, que puede realizarse sin peligro hasta un mes antes de la fecha final de la gestación, si bien deben elegirse fármacos atóxicos, especialmente antibióticos, y rechazarse los sistemas de columnización vaginal, así como el empleo de baños fríos o calientes.

La ausencia de menstruación, factor que exacerba la tricomoniasis, es un elemento favorable para conseguir la fácil curación del proceso.

Focos extravaginales y recidivas. Criterio de curación. Las recidivas sobrevienen generalmente por el acantonamiento del parásito en determinados focos extravaginales: uretra, vegija $\mathrm{y}$ glándulas vestibulares. Comprobada la existencia de tricomonas en estos reductos, es imprescindible el tratamiento tópico en los mismos, utilizando soluciones con las que se puedan practicar instilaciones vesicales e inyecciones intraglandulares. De óptimo resultado son las suspensiones o disoluciones de antibióticos, y, en su defecto, de picrato de plata. En cuanto al criterio de curación, tratándose de una entidad tan recidivante, es preciso saber cuándo puede darse de alta definitiva a una paciente, con relativa seguridad de haber concluído su tratamiento. Puesto que la hemorragia menstrual es un reactivador de la vitalidad del flagelado, las exploraciones de confirmación deben realizarse a continuación de las reglas. Exámenes negativos, con resultados concordantes durante 2 a 4 ciclos, después de tratamiento conducido con asiduidad, autorizan a suponer la curación definitiva de la infestación.

\section{BIBLIOGRAFIA}

1. W. STOECKEL.-“Tratado de Ginecología”. Página 151.

2. MARTINEZ ZULETA, MANUEL N.-“Tesis de grado". Tricomoniasis Vesical. 1952.

3. VELAZQUEZ, Profesor LORENZO.--"Formulario 1955".

4. RODRIGUEZ LOPEZ DEL LLANO G.--Apéndice al tratado de Ginecología del profesor W. Stoeckel.

5. LOWSLEY Y KERWING.-_"Tratado de Clínica Urológica”, volumen $2^{\circ}$, pág. 95 . 
6. STRAIN, R. E. J. Urology, 1945. T. 54: 483. Trichomonas in the male.

7. GOMEZ VESGA, HERNANDO.-“Algunas consideraciones sobre los flujos genitales". "Revista Colombiana de Ginecología y Obstetricia". Volu_ men 5, número 5. 1953. Página 260.

8. ASA C. CHANDLER.- “Introduction to Parasitology". 1950. Volumen 1ํ. página 124 .

9. CORTES MENDOZA, EDUARDO.-"Patología Tropical". Página 282.

10. GOMEZ VESGA, HERNANDO.-Citado anteriormente.

11. VELAZQUEZ, Profesor LORENZO.-Citado anteriormente.

12. O. BLANCHARD.- “Tricomoniasis Vaginal”, Buenos Aires. 1947.

13. Citado por Rodríguez López del Llano, G.

14. GOMEZ VESGA, HERNANDO.-Citado anteriormente.

15. ANGEL GILBERTO.- "El Laboratorio en el Diagnóstico Diferencial de los Flujos Vaginales". "Revista de la Facultad de Medicina". Volumen XVIII, número 11, mayo de 1950. Bogotá.

16. RODRIGUEZ LOPEZ DEL LLANO.-Citado anteriormente.

17. Citado por W. Stoeckel.

18. Citado por W. Stoeckel.

19. GREENHALT. R. B. and BARFIELD, W. E.-Aureomycin in the Therapy of Trichomonas vaginalis vaginitis. American Journal of Obst. and Gynec. 62: 423-436. 1951.

\section{OBITUARIO}

La Dirección de la "Revista Colombiana de Obstetricia y Ginecoiogía" registra con profundo pesar la desaparición de las siguientes personas:

Señor don Luis Lleras Codazzi, padre del Profesor Santiago Lleras Codazzi, Presidente de la Sociedad Colombiana de Obstetricia y Ginecología.

Señor don José Amaya Olarte, padre del señor Profesor Hernando Amaya León, antiguo director de la Revista.

Señora doña Eva Rodríguez de Novoa, madre del doctor Carlos Novoa Rodriguez, actual Secretario General de la Sociedad. Seoñra María Gaitán de Pedraza, madre del doctor Jaime Pedraza Gaitán, miembro de Número de la Sociedad.

Para los distinguidos colegas nuestra sincera manifestación de condolencia. 